\title{
A Invenção Técnica: transindividualidade e agenciamento coletivo
}

\section{The technical invention: transindividual and collective assemblage}

\section{Resumo:}

A partir de uma rede de pensadores, dentre os quais se destacam Gilbert Simondon, Gilles Deleuze e Félix Guatarri, a invenção técnica é definida como resultado de uma relação transindividual e como efeito de agenciamentos coletivos entre homem e matéria, ou, entre homem e mundo. Tratase de uma concepção de invenção que se afasta totalmente da idéia de uma operação intelectual ou uma construção mental projetada fora de qualquer relação com o meio.

Palavras-Chave: Invenção técnica. Transindividual. Agenciamento coletivo. Simondon. Deleuze. Guattari.

\section{Abstract:}

Inspired on a thinkers network, from which we emphasize Gilbert Simondon, Gilles Deleuze and Féliz Guatarri, technical invention has its definition as a result from a transindividual relation and as a collective assemblage effect between man and substance, or between man and world. It refers to a conception of invention that completely deviates from some intellectual operation or mental construction, disentailed from any relation with the environment.

Keywords: Technical invention. Transindividual. Collective assemblage. Simondon. Deleuze. Guattari.
ESCÓSSIA, Liliana da. A Invenção Técnica: transindividualidade e agenciamento coletivo. Informática na Educação: teoria \& prática, Porto Alegre, v. 13, n. 2, p. 16-25, jul./ dez. 2010.

\section{Liliana da Escóssia \\ Universidade Federal de Sergipe}

\section{Introdução}

A invenção é um tema que atravessa toda a obra de Gilbert Simondon. Se em Du mode d'existence des objets techniques o conceito de invenção técnica aparece como dispositivo analítico da realidade técnica, em L'individuation psychique et collective Simondon (1989) define a invenção como resultado de uma relação coletiva transindividual, definindo tal relação como aquela que se dá não entre indivíduos constituídos mas entre realidades pré-individuais.

O pré-individual é entendido como uma dimensão mais vasta e mais rica que o indivíduo, na medida em que comporta "[...] além da individualidade do ser individuado, uma certa carga de natureza, do ser não individuado [...]" (SIMONDON, 1989, p. 248). Para Simondon, não há indivíduo psíquico fechado, a individuação psíquica é permanente e implica sempre uma dimensão coletiva, da qual participa o sujeito e não o indivíduo. Embora carregue virtualidades pré-individuais - são elas que convocam novas individuações e criam novas problemáticas - o indivíduo isolado não consegue dar continuidade ao processo de individuação permanente para o qual é convocado. Somente quando conectada a outra, a carga pré-individual adquire potencial para operar uma nova individuação, a do coletivo, que ocorre de forma simultânea. 
O coletivo transindividual deve ser apreendido, portanto, como a reunião de sujeitos - portadores de realidade individuada e préindividuada. Não se trata de um meio exterior ao indivíduo, mas de uma rede de conexões da qual ele faz parte e que se exprime sob a forma de realidade transindividual: nem interior nem exterior ao indivíduo, tal realidade se constitui como espaço limite entre exterioridade e interioridade, um fora interior, cuja relação com o indivíduo é de prolongamento e não de oposição.

Resulta que a invenção é uma operação do sujeito já que é este quem comparece numa relação transindividual. Embora utilize a palavra sujeito, Simondon (1989) se afasta totalmente de uma visão substancialista da subjetividade. Nele, o sujeito não é um dado, um ponto de partida, uma essência, uma entidade estável com identidade fixada, mas resultado de um processo no qual emergem indivíduo psíquico e meio. Assim, não pode ser considerado uma fase do ser oposta ao objeto, mas a unidade condensada e sistematizada de três fases do ser : pré-individual, individual e transindividual. Essas fases "[...] corresponderiam parcialmente, mas não completamente, ao que é designado [respectivamente] pelos conceitos de natureza, indivíduo, espiritualidade [...]" (SIMONDON, 1989, p. 205).

\section{Objeto Técnico e Processo de Concretização: a matéria como informação}

Suporte e símbolo da relação transindividual. É assim que Simondon situa o objeto técnico em sua rede conceitual, afirmando que este traz consigo algo do ser que o inventou - algo da natureza humana - entendida aqui como "[...] o que resta de original, de anterior mesmo à humanidade constituída no homem [...]" (SIMONDON, 1989, p. 248). O homem, ao inventar, emprega seu natural, seu apeiron, que embora ligado a cada ser individual, não lhe pertence. Dito de outra maneira, o objeto traz consigo algo dessa dimensão préindividual, que é também natural e coletiva. Dimensão apontada de forma vibrante e poética por Michel Serres (1995), quando este se refere a uma memória e inteligência dos objetos técnicos:
A memória dorme na biblioteca, no museu, na tela do meu computador e na linguagem, escrita ou falada; a lembrança desperta e resplandesce na passagem da corrente; a imaginação acende, apaga ou acaba nas telas de televisão [...] grita a estridente flauta de Pan, canta a clarineta, chora o violão, soluça o baixo, sensibilidade de cobre, de corda e madeira [...] não, não somos tão excepcionais: o que os velhos livros chamavam nossas faculdades, ei-las, fora, espalhadas no universo inerte e fabricado. (SERRES, 1995, p. 48)

Quase-sujeitos técnicos. É assim que Serres denomina os objetos inventados pelos homens: objetos que pensam por eles, com eles e entre eles, não podendo ser reduzidos a simples coisas. Objetos não-passivos, conforme fica claro na forma como nos fala da relação do jogador com a bola:

\begin{abstract}
Veja aqueles garotos jogando bola: os desajeitados tomam a bola como um objeto, enquanto os mais espertos servem-na como se ela lhes fosse superior; eles se adaptam aos passos e recuos. Acreditamos que sujeitos manipulam esta bola inflada; puro engano - ela traça suas relações. Para seguir sua trajetória é que a equipe se cria, se conhece, se apresenta. Sim, ativa, a bola joga. (SERRES, 1995, p. 47-48)
\end{abstract}

A idéia presente, tanto em Simondon quanto em Serres, é a de que os objetos técnicos são portadores de sentido, mensageiros que emitem, transportam e veiculam informações. Ou seja, a matéria - viva ou inerte - informa, em dois sentidos: informa porque transmite informação e informa no sentido de que a forma está presente na própria matéria, ao invés de ser dada por algo exterior a ela. Isso determina uma maneira de conceber a relação do homem com a técnica que se afasta do esquema hilemórfico de forma e matéria. Aqui, a relação do homem com a matéria - com a natureza e com os objetos - é uma relação não de formatação, mas de agenciamento, acoplamento ou composição entre duas formas.

Uma vez inventado pelo homem, o objeto técnico adquire, ao longo de um phylum evolutivo - que é o seu processo de concretização - um modo de existência original, uma dinâmica própria: uma forma de individualidade. Mas a própria operação de invenção não pode ser pensada como uma operação intelectual do homem, como uma construção mental projetada fora de qualquer relação com um meio. Para Simondon (1989) a invenção se dá num plano de virtualidades que não tem nada de 
abstrato, no sentido de se opor a algo concreto, real. A virtualidade da invenção técnica é o que há de mais concreto. Ela deve ser compreendida em função da tecnicidade da matéria.

A tecnicidade relaciona-se à natureza dos elementos, às propriedades da matéria, por exemplo, a natureza das fibras de sisal e da madeira, a consistência da argila, a densidade e o brilho do ouro, a leveza e dureza do silício ${ }^{1}$. Todas essas propriedades exercem um papel fundamental na invenção, portanto, na constituição do virtual: a matéria é informação e energia. O ato de invenção traz à tona um certo vitalismo da matéria - poderíamos dizer, uma autopoiese 2 .

Em Tecnologia: mito e realidade, Laymert Garcia dos Santos (1992) aborda o processo de autopoiese da matéria através de uma noção muito utilizada por Simondon, desenvolvida por Deleuze/Guattari em Mil Platôs: a linhagem tecnológica, entendida como fio condutor que une os primeiros achados de sílex aos moderníssimos chips de silício. Considerando que o sílex e o silício pertencem a uma mesma linhagem, podemos dizer que não existe eletrônica que não passe pela metalurgia. Não se trata de uma cronologia de invenções. A temporalidade da técnica é pensada a partir de uma dinâmica ditada pela matéria e não por uma filiação monótona de um objeto a outro. Se há um continum tecnológico, este só pode ser definido, segundo Deleuze e Guattari (1997, p. 88), como "[...] fluxo de matéria-movimento, fluxo de matéria em variação contínua, portador de singularidades e de traços de expressão [...]".

Ou, como afirma Santos, como

\footnotetext{
1 Interessante saber que esse elemento químico tão usado na eletrônica, e portanto nas redes de conexões informacionais, apresenta, ele próprio, as propriedades de conexão. O silício desempenha, em relação aos corpos minerais, um papel muito parecido com o do carbono para os corpos vivos: o carbono possui a propriedade singular de seus átomos ligarem-se uns aos outros, formando longas cadeias que possibilitam a existência de moléculas muito grandes e complexas, tais como as de proteínas. O silício apresenta uma propriedade parecida, que o possibilita igualmente formar longas cadeias. (ENCICLOPÉDIA, 1995, FERREIRA, 1986)

2 A noção de autopoiese é formulada por Maturana e Varela (1980). Ao se contraporem à definição dos seres vivos como sistemas de tratamento de informação, esses autores propõem que tais sistemas sejam apreendidos como seres em constante processo de auto-criação, de produção de si (KASTRUP, 1995). Utilizamos tal noção como metáfora para pensar essa inventividade própria da matéria, tendo claro entretanto, que no processo de invençãoem técnica, o ato humano é imprescindível.
}

[...] uma espécie de fio dinâmico cuja consistência é feita de propriedades da matéria, mas também de intuições, de afetos, de oportunidades, de pensamentos, de explorações, de saberes, de desejos, de tradições, de interferências e conexões de toda ordem, que se cristalizam em invenções. (SANTOS, 1992, p. 24)

Através do exemplo da espada de ferro e do sabre de aço Deleuze e Guattari (1997) nos mostra que no desenvolvimento da metalurgia podemos encontrar várias linhagens. A espada de ferro e o sabre pertencem a linhagens diferentes na medida em que cada uma apresenta variações que podem ser agrupadas em dois planos: no primeiro, as singularidades ou ecceidades espaço-temporais de diferentes ordens, assim como as operações que lhes são associadas; no segundo plano, as qualidades afetivas ou traços de expressão de diferentes níveis, que correspondem a estas singularidades e operações. Assim, cada linhagem, ou cada phylum maquínico - para usar uma expressão de Deleuze e Guattari (1997, p. 88) - "[...] tem suas singularidades e operações, suas qualidades e traços, que determinam a relação do desejo com o elemento técnico (os afetos 'do' sabre não são os mesmos que os 'da' espada) [...]". Mas o que há, no limite, a despeito de toda singularidade, é uma só linhagem filogenética, um só phylum maquínico idealmente contínuo, que é ao mesmo tempo natural e artificial. Fluxo operatório e expressivo de uma certa unidade do homem com a natureza. Um dos aspectos destacados por Garcia dos Santos (1992) nas análises de Deleuze e Guattari, relativas à invenção técnica, é justamente essa unidade do homem com a natureza, processo através do qual o homem segue o fluxo da matéria e o faz produzir a partir de suas virtualidades, interferindo e favorecendo certas variações. Tal processo é denominado agenciamento. Para estes pensadores,

[...] chama-se agenciamento todo conjunto de singularidades e de traços extraídos do fluxo selecionados, organizados, estratificados - de maneira a convergir (consistência) artificialmente e naturalmente: um agenciamento, nesse sentido, é uma verdadeira invenção. (DELEUZE; GUATTARI, 1980, p. 506)

Assim, um agenciamento é mais que o resultado de um processo de diferenciação do phylum maquínico, ele é o próprio processo de 
diferenciação. Os agenciamentos diferenciam e dividem o fluxo introduzindo descontinuidades na continuidade ideal da matéria-movimento. Com isso, produzem vastos agrupamentos que constituem culturas ou idades, como a idade dos metais ou da eletrônica. Mas, se há essa ação seletiva dos agenciamentos sobre o phylum maquínico, há também a reação evolutiva do phylum atravessando todos os agenciamentos. Há, como afirma Leroi-Gourhan (1984), um élan vital tecnológico, que vai constituindo a matéria e se encarnando numa forma. Tal vitalismo tecnológico é denominado por ele de tendência técnica. O fluxo da matéria, ou melhor, essa dinâmica que se estabelece entre agenciamentos e fluxo maquínico, é pura produtividade, ou pura tecnicidade conceito forjado por Simondon (1958) para falar do aspecto de concretude das virtualidades da matéria. Esse processo no qual o homem segue o fluxo da matéria é ilustrado em Mil Platôs com um texto de Elie Faure no qual ele evoca a ação/relação de povos itinerantes da índia numa mina de granito:

A beira do mar, no limiar de uma montanha, encontravam uma muralha de granito. Então, entravam todos no granito, viviam, amavam, trabalhavam, morriam, nasciam na obscuridade, e três ou quatro séculos depois saíam novamente, a léguas de distância, tendo atravessado a montanha. Atrás deles, deixavam a rocha vazada, as galerias cavadas em todos os sentidos, paredes esculpidas, cinzeladas, pilares naturais ou factícios escavados, dez mil figuras horríveis ou encantadoras. [...] O homem aqui consente, sem combate, à sua força e a seu nada. Não exige da forma a afirmação de um ideal determinado. Ele a extrai bruta do informe, tal como o informe quer. Utiliza as cavidades de sombra e os acidentes do rochedo. (DELEUZE; GUATTARI, 1997, p. 98)

\section{Meio Associado e Autopoiese da Matéria}

Em todo processo de individuação o indivíduo é apenas um aspecto do processo, um lado do desdobramento do ser, o outro é o meio associado, que emerge de forma simultânea ao indivíduo. Através desse conceito de meio associado Simondon (1958) presta uma enorme contribuição à reflexão contemporâ- nea sobre a relação homem-técnica ou técnica-natureza. Para ele, na invenção técnica não há simplesmente a introdução de um novo tipo de ser, inteiramente distinto dos seres naturais. Há criação de uma nova dimensão onde se efetuam relações de causalidade recíproca entre indivíduo técnico e meio,

[...] um meio que o ser técnico cria em torno de si e que o condiciona assim como é condicionado por ele. Esse meio por sua vez técnico e natural pode ser nomeado meio associado. É através dele que o ser técnico se auto-condiciona em seu funcionamento [...] (SIMONDON, 1958, p. 57).

O que remete à dimensão autopoiética da matéria, no sentido de que um certo regime de elementos naturais participaria da constituição do ser técnico. O meio associado comparece aqui como "[...] mediador da relação entre os elementos técnicos fabricados e os elementos naturais, no seio dos quais funciona o ser técnico [...]" (SIMONDON, 1958, p. 57).

Trata-se de uma nova concepção da relação técnica-natureza pois não há um meio natural como um dado a priori. Há um campo onde se redeterminam potencialidades da natureza. 0 meio associado é justamente o espaço híbrido, misto de natureza e técnica. Espaço este que é condição de funcionamento do objeto técnico, ao mesmo tempo em que a individuação do objeto é condição de criação deste espaço: objeto e meio são correlatos num mesmo ato de invenção. A importância da idéia de causalidade recíproca reside no fato de ser ela que rege qualquer processo de individuação, e não apenas a individuação dos objetos técnicos. A causalidade recíproca caracteriza igualmente o dinamismo do pensamento no processo de invenção. Com base nisto é estabelecida uma analogia entre o modo de existência do ser vivo e do ser técnico, no qual pode-se afirmar que "[...] os esquemas mentais reagem uns sobre os outros durante a invenção como os diversos dinamismos do objeto técnico reagem uns sobre os outros em seu funcionamento material [...]" ( SIMONDON, 1958, p. 28). É porque carrega consigo seu meio associado que o ser vivo pode inventar objetos que se auto-condicionam.

Ao contrário do que acontece na Psicologia da Forma, há um privilégio do fundo em detrimento das formas. O meio associado é o fundo dinâmico, o sistema de virtualidades e de forças sobre o qual se afrontam e se com- 
binam os esquemas, as operações e as formas. Portador dos dinamismos, ele veicula informações capazes de transformar o sistema. A invenção técnica, entendida como operação paradigmática da individuação psicossocial, é definida mais uma vez em função das relações do atual com o virtual. Os esquemas, operações ou formas técnicas, são atualizações do sistema de virtualidades, e enquanto tal são passivas, tornando-se ativas somente em suas relações com o virtual, com o meio associado, através do jogo de causalidade recíproca.

Essa noção de meio associado está diretamente relacionada com a definição da técnica como instância problemática. A antecipação do esquema técnico no ato da invenção, antes de ser uma solução de problemas, é a criação ou introdução de problemas. Isso porque, na invenção, não se parte de condições estabelecidas anteriormente pelo mundo natural ou geográfico, ou, dito de outra forma, não se trata de uma escolha entre soluções existentes. A condição primeira de uma instância problemática é justamente a experimentação.

A idéia de autonomia técnica só pode ser pensada se entendermos por autonomia a autopoiese da matéria e a conseqüente tendência à concretização, através de uma sobredeterminação funcional. Para compreender a dinâmica tecnocientífica é preciso reconhecer que sua constituição e sua evolução - para as quais os homens são certamente indispensáveis - respondem a fluxos próprios nos quais as considerações psicológicas, econômicas, sociais e políticas não são suficientes para explicá-los. Isso não deve ser confundido com a afirmação de uma autonomia do sistema técnico, em suas versões apologéticas - a saber, a cibernética -, ou catastróficas - por exemplo, a concepção de um sistema técnico autônomo, inteiramente independente da vontade humana, conforme denunciado por Ellul (1977). Trata-se apenas de dizer que as interferências psico-sócio-econômico-políticas na dinâmica tecnocientífica não dão conta de sua especificidade. Um dos esforços de Simondon (1958) é justamente o de marcar sua diferença com relação ao pensamento tecnicista - no qual a máquina é concebida à semelhança do vivo, possuindo assim a capacidade de alterar sua conduta, de se auto-reproduzir. A dinâmica evolutiva da técnica é o próprio tempo da técnica - sua historicida. É o que Ihe dá consistência.
Há, segundo Bruno Paradis (1989), duas noções de temporalidade técnica em Simondon: a temporalidade do indivíduo técnico - o processo de concretização -, onde a gênese do objeto técnico se dá por ressonância interna, em uma sinergia de funções que vai do abstrato para o concreto; e a temporalidade ou devir da própria técnica tomada em seu conjunto, no qual a evolução da realidade técnica é pensada a partir de uma problemática da transdução. ${ }^{3}$ Paradis (1989) ressalta que, ao introduzir essa questão do tempo, Simondon renova profundamente a reflexão sobre a técnica, já que "[...] a afirmação de um devir constitutivo do objeto técnico repousa sobre o acoplamento do indivíduo e de seu 'meio associado' e significa a crítica do esquema hilemórfico, assim como da distinção meio/fim [...]" (PARADIS, 1989, p. 221). A técnica é concebida como instância problemática, tendo em vista sua abertura ao futuro, sua determinação em função do virtual. Mas isso remete necessariamente à questão da função inventiva, pois é ela que abre o indivíduo técnico ao devir.

Pode parecer, por outro lado, que a afirmação de uma dinâmica própria aos objetos técnicos estaria em contraposição ao que é tão enfatizado por B. Latour (1996): a idéia de que as técnicas estão impregnadas de paixão, subjetividade e interesses sociais. No entanto, o próprio Latour, ao analisar essa questão da autonomia afirma que, embora inventados pelos homens para atender a determinadas finalidades sociais, morais e políticas, os objetos técnicos "[...] encerram uma incerteza ligada ao fato de que todos os objetos que inventamos nos ultrapassam [...]" (LATOUR, 1996, p. 165), enfatizando com isso o caráter imprevisível dos fins na dinâmica técnica.

O ser técnico conserva uma certa independência com relação ao seu inventor, na medida em que pode tornar-se um elo numa cadeia, numa série não prevista por ele, operando uma espécie de desvio das ações previstas. No entanto, tal desvio só é possível porque o homem integra o objeto técnico num conjunto técnico coordenado. É a isto que LeroiGourhan (1984) se refere quando afirma que o fato técnico não pode ser reduzido ao objeto,

3 "Por transdução entendemos uma operação física, biológica, mental, social pela qual uma atividade se propraga gradativamente no interior de um domínio [...] é aparição correlativa de dimensões e de estruturas em um ser em estado de tensão pré-individual [...]" (SIMONDON, 1989, p. 18-19). 
pois este não é nada, fora do conjunto técnico a que pertence. Ou seja, não existe o instrumento puro, fora das destrezas corporais e mentais que condicionam sua utilização. Dito de outra, forma, se há uma dinâmica própria ao objeto técnico tendendo à concretização, quase que uma inventividade do próprio objeto, isso supõe uma função inventiva do homem, que por sua vez se atualiza no agenciamento com os objetos, com o mundo.

\section{Mediação, Assimetria e Complementaridade na Relação Homem-Máquina}

A partir de um certo momento na história das tecnologias - ou, na história das relações do homem com a técnica - vimos operar, pela cultura, uma atitude de dupla recusa com relação ao objeto técnico: por um lado, os objetos técnicos são considerados como puros aglomerados de matérias, instrumentos utilizados a serviço do homem e desprovidos de significação; por outro, são vistos como seres autônomos e potenciais inimigos da humanidade.

Essa atitude de recusa tem início com a chegada da termodinâmica. A idéia de progresso contínuo que iria melhorar o destino do homem, própria da ciência clássica-mecânica, é substituída por uma noção de progresso agressivo e angustiante, pois a termodinâmica, além de representar uma violação irrestrita da natureza, cria uma máquina que passa a substituir o homem enquanto indivíduo técnico. Com a termodinâmica o homem deixa de ser o suporte da individuação técnica, pois o objeto técnico passa a ser indivíduo técnico. $\mathrm{O}$ homem se sente substituído e subjugado pela máquina. Com o surgimento da cibernética a ameaça de substituição é potencializada, deflagrando um acelerado processo de desestabilização do humano, tal como concebido pela modernidade. Pois, se o modelo máquina acionado no século XVII com a ciência moderna estabelecia uma identidade entre o organismo (humano e animal) e a máquina, tornando possível a simulação do organismo vivo, com o advento da cibernética o programa de simulação se expande. Segundo Eduardo Passos (1996) a simulação é estendida ao que até então era considerado humano por excelência: o espírito, entendido como realidade inextensa, como forma pensante e modeladora do universo. A nova ciência teve como meta a simulação da inteligência humana através da criação de uma máquina intencional: uma máquina sensível às informações do meio e que através de um mecanismo de retroalimentação fosse capaz de alterar sua própria conduta, de se auto-reproduzir.

Embora o projeto cibernético não tenha até hoje atingido seu objetivo - o que foi pensado para ser uma máquina inteligente não conseguiu até hoje passar do nível do automatismo - sabemos dos efeitos de desestabilização provocados na imagem-homem forjada pela modernidade, e conseqüentemente na relação do homem com a máquina. Conforme nos diz Passos (1996, p. 40), "[...] é em uma certa relação com a máquina que o homem perde sua identidade teórica e imaginária, desfazendo-se a sua unidade que por tanto tempo se acreditou imutável como a natureza ou os universais $[\ldots]^{\prime \prime}$.

Ao tentar produzir a réplica da inteligência humana - o que significaria sintetizar o seu espírito - o neo-mecanicismo cibernético estabelece uma nova relação homem-máquina, colocando em questão os princípios humanistas sobre os quais se havia assentado o mecanicismo cartesiano. Enquanto este afirmava uma identidade entre a forma aparente do homem e a máquina, o neo-mecanicismo propõe uma identidade funcional do pensamento. $O$ robô é precisamente a máquina que, através de uma operação mítica e imaginária, é transformada num duplo do homem. Tal operação, segundo Simondon (1958), resulta de uma aspiração tecnocrática de poder incondicional. O fato é que a promessa de máquinas inteligentes e autônomas produziu uma desestabilização na imagem-homem do pensamento moderno, na medida em que implicou imediatamente o "[...] desaparecimento do humano enquanto forma de identidade do pensamento [...]" (PASSOS, 1996, p. 42), o que foi vivido pelo homem como uma perigosa ameaça. $O$ mito de Frankenstein, no qual a criatura se volta contra o criador, e os andróides - as máquinas desejantes do filme Blade Runner, de Ridley Scott, expressam, cada um a seu modo, - imaginário de uma cultura temerosa das máquinas autônomas. No caso dos andróides, o que eles desejam "[...] é se efetivarem como máquinas temporais [...]" (PASSOS, 1996, p. 47), ou seja, se transformarem e evoluírem no 
tempo, formulando para si outros problemas que não aqueles previstos pelos seus criadores. Eles lutam "[...] pela manutenção do tempo de suas maquinações [...]" (PASSOS, 1996, p. 47), e nisso consiste a grande ameaça expressa no filme.

A suposta autonomia das máquinas se constitui como um dos eixos da dupla recusa das técnicas. Embora portadora de uma contradição interna, tal recusa possui um sentido estratégico. Ao considerar o objeto técnico como simples ferramenta a serviço do homem, a cultura tenta afastar a hipótese contrária e ameaçadora que seria a dominação do homem pela técnica - o homem a serviço da máquina. A origem de tal sentimento de ameaça e a conseqüente atitude de recusa é a crença numa relação simétrica entre homem e máquina, resultando em duas formulações: na primeira a máquina é identificada ao homem, na segunda, o homem é identificado à máquina. No primeiro caso, a máquina torna-se uma propriedade do homem, uma criatura que the serve em suas necessidades e alimenta seus fantasmas mais singulares. Há aqui uma assimilação despótica da máquina pelo homem.

No segundo caso, que é inverso, porém complementar, o homem serve à máquina - a essa máquina mais vasta que é a comunidade ${ }^{4}$. Cabe esclarecer que, em suas referências ao coletivo, Simondon (1989) distingue o conceito de comunidade do de sociedade. Para ele a realidade coletiva é indissociavelmente comunitária e social: mas as duas são características antagônicas. A comunidade reagrupa os indivíduos a partir de suas funções, destituindo-os de seu potencial de individuação permanente, automatizando-os e tornando-se ela própria um autômato. A comunidade é fechada e nãoevolutiva. Esse é o ideal das sociedades tecnocráticas baseadas no modelo de autoregulação cibernética. Uma sociedade, ao contrário, revela $o$ aspecto de individuação permanente do coletivo, das individuações tensionais e convergentes de seus membros. Evolutiva, aberta

4 Essa distinção está bem próxima daquela estabelecida por Canguilhem, mais especificamente em El vivente y su médio e em El conocimiento de la vida, editado pela Anagrama, Barcelona, 1976. Ao abordar o problema do homem como organismo social, Simondon (1989) afirma que uma sociedade é, ao mesmo tempo, máquina e organismo. A dimensão máquina é o aspecto de programação e estereotipia (comunidade). A dimensão organismo é o aspecto de improvisação, de experimentação com o meio - de transformação - que caracteriza todo organismo vivo e também a individuação permanente do social. e inacabada uma sociedade abre o sentido de sua expansão no espaço e no tempo, se transformando e incorporando criações.

Sendo assim, a integração do indivíduo na comunidade, numa civilização fortemente industrializada - onde tal integração passa necessariamente pela máquina -, tem redundado numa assimilação dos valores fundamentais do automatismo. Isso resulta numa estereotipia de condutas individuais e sociais. Indivíduo e sociedade são identificados e reduzidos a meros autômatos.

Como vimos, as duas formulações, embora antagônicas, se baseiam numa idéia de simetria como princípio da relação homem-técnica. Simondon (1958) vai se contrapor a essa idéia, afirmando que esta relação é assimétrica $e$ complementar. Mais ainda: ela é duplamente ontogenética - tem valor de devir -, na medida em que homem e máquina se constituem na relação, não são termos dados a priori.

Na relação complementar e assimétrica, o homem é um ser inacabado que a máquina completa (temporariamente), e a máquina é um ser que encontra no homem sua unidade, sua finalidade e sua ligação ao conjunto do mundo técnico. Nesse sentido, homem e máquina são mutuamente mediadores:

[...] a máquina possui em suas características a integração à espacialidade e a capacidade de reter a informação através dos tempos, enquanto o homem, por suas faculdades de conhecimento e seu poder de ação, integra a máquina num universo de símbolos que não é espaço-temporal e no qual a máquina não poderia jamais ser integrada por si mesma [...] (SIMONDON, 1989, p. 278).

Em tal relação, porém, não há redução da máquina ao homem ou do homem à máquina. Máquina e homem devêm na relação, no acoplamento de um ao outro. O que podemos dizer, sem contrariar o princípio de complementaridade, e sem cair numa idéia de simetria entre homem e máquina, é que sendo a invenção técnica um ato humano, os produtos de tal invenção - os objetos técnicos - fazem parte do mundo humano. Não se trata, porém, de uma integração harmônica, uma complementaridade passiva, sem luta. Há diferentes formas de se conceber a complementaridade. Uma delas é acreditar que tudo se integra em uma vontade universal: tal é a suposição da finalidade divina, onde Deus é invocado como 
condição de complementaridade, já que há, por princípio, uma inadequação entre os seres, como conseqüência de uma falta de simetria entre o ser criador e os seres criados. A crença na possibilidade indefinida de progresso também expressa a busca de integração baseada no princípio da universalização - a universalização do princípio da razão.

Em oposição a essa forma de complementaridade característica da religião e da tecnocracia, há um tipo de complementaridade tal como concebida pelos pré-socráticos: como dupla de contrários, nascimento e morte onde a morte de um ser é condição de nascimento do outro - subida e descida -, caminho para o alto e caminho para baixo. Nesse ponto, Nietzsche é convocado para melhor caracterizar a relação complementar: "[...] é a complementaridade da soma do devir, que tem por expressão o eterno retorno que Nietzsche reconhece como um mito essencial nos pré-socráticos e que ele integra em seu panteísmo." (SIMONDON, 1989, p. 250)

Trata-se de uma relação de soma ou composição que se dá não através de uma harmonia, mas ao contrário, implica sempre em luta e violência, conforme esclarece o próprio Nietzsche em A Genealogia da Moral:

[...] o 'desenvolvimento' de uma coisa, um uso de um órgão, é tudo menos o seu progressus em direção a uma meta, menos um progressus lógico e rápido, obtido com um dispêndio mínimo de forças - mas sim a sucessão de processos de subjugamentos que nela ocorrem [...] com as resistências que a cada vez encontram, as metamorfoses tentadas [...] (NIETZSCHE, 1987, p. 82).

Se a idéia de simetria é recusada para caracterizar a relação homem-máquina, o mesmo não acontece quando ele se refere à relação homem/mundo. A relação assimétrica - entre homem e máquina - institui uma relação simétrica entre homem e mundo, sujeito e objeto. O homem cria a máquina para que ela institua tal relação, e isso se dá através de sua dupla função mediadora: como ferramenta e como instrumento. Há uma importante distinção entre esses dois conceitos. A máquina é ferramenta na medida em que permite ao sujeito agir sobre o objeto, prolongando e armando o corpo para efetuar um gesto; é instrumento na medida em que leva ao sujeito sinais vindo do objeto, prolongando e adaptando o corpo para obter uma percep- ção ampliada. $O$ instrumento é ferramenta da percepção. $O$ objeto técnico institui assim um ciclo, que vai do sujeito ao objeto e do objeto ao sujeito: "[...] veicula, amplifica, transforma, traduz e conduz em um sentido uma ação, em outro sentido uma informação." (SIMONDON, 1989 , p. 282)

Essa é uma diferença fundamental ressaltada por Santos (1995). Ele afirma que uma nova relação homem-técnica passa pela apreensão da técnica como instrumento. É preciso conceber a técnica como instrumento que colhe uma informação do mundo, dando-lhe visibilidade, sem necessariamente ter uma ação sobre ele. A fotografia e o cinema são citados como casos ilustrativos dessa relação homem/instrumento, na qual se colhe uma informação de natureza diversa daquela coIhida por uma percepção puramente humana. No caso da fotografia a relação torna visível a realidade escondida no movimento; no caso do cinema a relação torna visíveis impressões do tempo. Não se trata, contudo, de manter dois tipos de percepção - a percepção direta do homem e a percepção indireta, que passa pelo instrumento, mas de experimentar sempre uma percepção direta, com ou sem instrumento: expor-se à qualidade da informação como sinal do tempo e do movimento. É o que podemos fazer, segundo Santos (1995), com a nossa percepção da relação homem-máquina. Isso nos levaria a compreender profundamente a tecnicidade e conseqüentemente a especificidade do ser vivo diante do mecânico.

\section{Invenção Técnica Como Individuação Coletiva}

A oposição criada a partir de um certo momento da história entre cultura e técnica colocou os objetos técnicos fora do mundo das significações e dos valores culturais, conferindo-lhe uma função meramente utilitária. A abordagem ontogenética ${ }^{5}$ da técnica restitui o caráter mediador dos objetos técnicos e expressa, de forma contundente, a busca de uma superação das dicotomias utilizadas tra-

5 Em Relação Homem-Técnica e Processo de Individuação definimos a abordagem ontogenética da técnica como aquela que "[...] considera a técnica em sua estreita vinculação com o devir coletivo e com o mundo das significações da cultura [...]" (ESCÓSSIA, 1999, p. 43). 
dicionalmente para pensar a realidade: nem instrumento neutro totalmente manipulável pelos homens, nem potência autônoma isolada, a técnica é mediadora entre a natureza e o homem e os objetos técnicos são seres intermediários, híbridos de natureza e cultura.
É isso que nos permite pensar a técnica como desdobramento do ser, como vetor de individuação coletiva. Ao se individuar, o objeto técnico cria um novo espaço-tempo, reinventando permanentemente a dinâmica no campo de subjetivação coletiva.

\section{Referências}

CANGUILHEM, G. El conocimiento de la vida. Barcelona: Anagrama, 1976.

DELEUZE, G. A propos de Gilbert Simondon: L'Individu et sa genèse physicobiologique. Revue Philosophique de la France et de l'Etranger, Paris, v. 156, p. 115-118, 1966.

DELEUZE, G.; GUATTARI, F. Mil Platôs: capitalismo e esquizofrenia. Rio de Janeiro: Ed. 34, 1997. V. 5.

ELLUL, J. Le système technicien. Paris: Calmann-Lévy, 1977.

ENCICLOPÉDIA Barsa. Rio de Janeiro: Encyclopaedia Britannica do Brasil, 1995. V. 14.

ESCÓSSIA, L. da. Por uma Ética da Metaestabilidade na Relação Homem-Técnica. Cadernos de Subjetividade, São Paulo, v. 1, p. 177-186, 1993.

ESCÓSSIA, L. da. Relação Homem-Técnica e Processo de Individuação. São Cristovão, SE: Ed. UFS/FOT, 1999.

FERREIRA, A.B. de H. Novo Dicionário [Aurélio] da Língua Portuguesa. 2. ed. rev. e aum. Rio de Janeiro: Ed. Nova Fronteira, 1986.

GUATTARI, F. Caosmose: um novo paradigma estético. Rio de Janeiro: Ed. 34, 1992.

KASTRUP, V. Autopoiese e subjetividade: sobre o uso da noção de autopoiese por G. Deleuze e F. Guattari. Revista do Departamento de Psicologia da UFF, Rio de Janeiro, v. 7, n. 1, p. 86 -97, 1995.

LATOUR, B. Jamais Fomos Modernos. Trad. de Carlos Irineu da Costa. Rio de Janeiro: Ed. 34, 1994.

LATOUR, B. Do Humano nas Técnicas. In: SCHEPS, R. (Org.). O Império das Técnicas. Trad. de Maria Lúcia Pereira. Campinas: Papirus, 1996. P. 155-166.

LEROI-GOURHAN, A. O Meio e as Técnicas. In: LEROI-GouRHAN, A. Evolução e técnicas. Lisboa: Ed. 70, 1984. V. 1.

LEROI-GOURHAN, A. O Homem e a Matéria. In: LEROI-GOURHAN, A. Evolução e técnicas. Lisboa: Ed. 70, 1984. V. 2.

MATURANA, H.; VARELA, F. Autopoiesis and cognition: the realization of the living. Dordrecht: D. Reidel, 1980.

NIETZSCHE, F.W. A Genealogia da Moral. Trad. Paulo César Souza. São Paulo: Brasiliense, 1987.

PARADIS, B. Le futur et l'épreuve de la pensée. Lendemains, Hitzeroth, v. 14, n. 53, p. 26-28, 1989.

PASSOS, E. Modelo Máquina e Subjetividade. Item, Rio de Janeiro, n. 3, p. .40-49., fev. 1996.

SANTOS, L.G. dos. "Tecnologia: mito e realidade". Revista Educação e Sociedade, no 41, Campinas/SP, p. 2129, Abril/1992

SANTOS, L.G. dos. O Homem e A Máquina. In: L. C. Junqueira Fo. (Org.). Corpo-Mente: Uma Fronteira Móvel. 1 ed. São Paulo: Ed. Casa do Psicólogo, 1995.

SCHEPS, R. (Org.). O Império das Técnicas. Campinas/SP: Papirus, 1996. 
SERRES, M. A Lenda dos Anjos. São Paulo: Aleph, 1995.

SIMONDON, G. Du mode d'existence des objets techniques. Paris: Aubier, 1958.

SIMONDON, G. L'Individu et sa genèse psysico-biologique. Paris: Presses Universitaires de France, 1964.

SIMONDON, G. L'Individuation psychique et colletive. Paris: Aubier, 1989.

SIMONDON, G. L'Invention dans les techniques: cours et conferences. Paris: Seuil, 2005.

Recebido em março de 2010.

Aprovado para publicação julho de 2010.

\section{Liliana da Escóssia}

Mestra em Psicologia (Psicologia Clínica) pela Pontifícia Universidade Católica de São Paulo, Doutora em Psicologia pela Universidade Federal do Rio de Janeiro e Doutora em Doutorado Sanduiche - Ecole Polytechnique de Paris - Centre de Recherche en Epistemologie Apliqué. Atualmente é professora adjunta da Universidade Federal de Sergipe. Aracajú-SE/Brasil. Email: liliana.em@infonet.com 